\title{
Main factors determining potential qualified appearance of pebble and effel dumps of depleted alluvial gold deposits
}

\author{
Gadzhi Mirzekhanov ${ }^{1,2^{*}}$, Zoya Mirzekhanova ${ }^{3}$. \\ ${ }^{1}$ Mining Institute of Far eastern branch of Russian Academy of Sciences, Khabarovsk, Russia. \\ "2SPC Kompas-Geoservis", LLC, Khabarovsk, Russia \\ ${ }^{3}$ FSBIS "Institute of Water and Environmental Problems", Far East Division of Russian Academy of \\ Sciences, Khabarovsk, Russia
}

\begin{abstract}
The influence of two most important factors determining gold losses during mining of alluvial deposits is considered. They include the granulometric composition of sands and the initial gold content in them. It is shown that the underestimation of these indicators in the assessment of anthropogenic deposits significantly reduces the resource attractiveness of depleted objects. Specific examples give calculations that allow for a more accurate predictive estimate of the resource potential of the dredging tailing (effel) dumps. Based on the consideration of natural and climatic factors in determining the conditions, the placer content is plotted for the gold content in the sands of various economic areas of Khabarovsk Region. It has been established that at the same values of the designed process loss and given the comparability of the main placer parameters, a high average gold content in the initial sands makes it possible to predict within the dump some objects with standard contents. Keywords: Alluvial deposits, factors, gold losses, dumps, conditions, effel, sand composition, initial contents
\end{abstract}

\section{Introduction}

Completeness of gold extraction from placer deposits is determined by the joint influence of various factors, which are manifested to some extent in the process of developing a site. There are more than 14 production and geological factors, which influence on gold losses can be taken into account to varying extent $[1,2,3]$. It is obvious that it is rather difficult to trace the influence of an individual factor per se, since they are interrelated, complementary or mutually exclusive. In general, such factors as gold granulometry and clayeyness, which determines the "rinsing" of sand, have been studied. The initial data of these parameters are used to calculate the process losses of metal during the mining of alluvial deposits. In most cases, the identified process losses are not so significant and amount to 5-10\%. Accepting process losses as a constant value, the authors reasonably predict in pebble-effel dumps the gold content of $30-100 \mathrm{mg} / \mathrm{m}^{3}$, which in most cases, using present process schemes, does

\footnotetext{
* Corresponding author: mgs_gold@mail.ru
} 
not enable to include them in the list of objects suitable for profitable re-development [4]. The predicted estimation of the resource potential of the precious metal in anthropogenic dumps of alluvial gold deposits in the regions of Far Eastern Federal District is significant, based on the above [5, 6, 7, 8]. Meanwhile, the share of forecasted resources in highly promising deposits, which are suitable under modern conditions for industrial processing, is negligible. It does not exceed $10 \%$. At the same time, studies and practical experience show that the influence on gold losses during the washing of productive sands of individual factors or their combination can rationalize the resource attractiveness of pebble-effel dumps, undoubtedly, suitable for repeated profitable mining. First of all, the granulometric composition of sands and the initial contents of gold in them can be classified as such.

\section{Methodology and Objects}

The work is based on the results of studies of pebble-effel dredged dumps of more than 50 of depleted and operating placer deposits of Far East. Wastes of alluvial gold mining are represented mainly by dumps of different genetic type, differing both by morphological, morphometric parameters, and by the composition of deposits and the resource possibilities of their subsequent processing.

The formation of the dump complex was studied by traditional methods: pebble-effel dumps of the spent placers were completely opened to the full depth by sweeps and ditches in which large-volume samples $\left(0.5-3 \mathrm{~m}^{3}\right)$ were taken every 10 meters. The gold content and the total volume of the dump were identified, which were compared with the initial data of spent placers. In developing placers, daily quality control of washing was carried out. In the selected samples, the following were determined: the gold content, the nature of change in the process loss of gold, depending on the degree of the effel volume of the original sands.

\section{Results and Discussion}

\subsection{Granulometric composition of sands}

An important condition in the formation of the resource prospects of a deposit is the ratio in the original gold-bearing sands of the effel (less than $80 \mathrm{~mm}$ ) and pebble (more than 80 $\mathrm{mm}$ ) fractions. In most cases, the fraction of the effel fraction $(\mathrm{Ke})$ in the sands varies in the range $60-80 \%$. But the placers are not an exception, where the pebble component predominates over effel $(\mathrm{Ke}=20-40 \%)$. It is extremely difficult to detect the influence of this factor on gold losses as a part of the combined effect of all factors during washing. The predominance of some or other fraction, of course, makes the process of sand disintegration difficult or, vice versa, easy. So increasing the share of a fraction less than $80 \mathrm{~mm}$ creates a viscous gravel-sand-water stream with a ratio of L:S (liquid to solid phase) of less than 10 . The flow of such a consistency, falling on the sluice, does not give gold to completely precipitate, which leads to an increase in loss. The degree of influence of this factor on process loss is generally insignificant. And only in extremely abnormal cases, when the share of the effel component exceeds $90 \%$, it is estimated at $20-30 \%$ of the calculated data [3]. Accordingly, such an influence, which is often compensated by the cumulative effect of other factors, is little manifested in the "industrial" form of the dumps.

It is another matter how the share of the effel component of the original sands is reflected in the gold content in the final products of their disintegration. When developing alluvial deposits, non-recoverable gold (process loss) is mainly concentrated in the effel 
dumps (90\%), as specified in the principal process scheme for washing gold-bearing sands, which makes them divided into two main components (pebble and effel). Based on the sand's effel content, the same amount of lost metal will be in different volumes of the dump. For example, when washing $1,000 \mathrm{~m}^{3}$ of sands containing $1 \mathrm{~g} / \mathrm{m}^{3}$ of gold with estimated process loss of 10\%, 100 grams of gold will be found in dumps, of which 90 grams $(90 \%)$ in effel. If in the sands $60 \%$ fall for effel size fraction, then 90 grams of metal are spread over the dump body of $600 \mathrm{~m}^{3}$, and if the share of this fraction is only $10 \%$, then it will be concentrated in a $100 \mathrm{~m}^{3}$ dump. With a constant amount of lost gold ( 90 grams), its content in each case will vary: in the first case it is $150 \mathrm{mg} / \mathrm{m}^{3}$, in the second $-900 \mathrm{mg}$ / $\mathrm{m}^{3}$, which is close to that in the original sands. Thus, the amount of technologically lost gold, expressed in terms of its content $\left(\mathrm{mg} / \mathrm{m}^{3}\right)$ in the effel dump has an inverse dependence on the effel of the original sands (Fig. 1). This pattern gives grounds to predict the possibility of having in the waste space highly promising dumplings with gold content, allowing them to be estimated as anthropogenic placers with conditioning parameters. The identification of "high" contents of a useful component in the effel dumps is always an occasion to search for the reasons that caused these anomalies.

In practice, in most cases, high gold content in the tested dumps is classified as excess losses, which is fundamentally wrong. For example, with the above parameters of washed sands $\left(1,000 \mathrm{mg} / \mathrm{m}^{3}\right), 20 \%$ of process loss and $10 \%$ effel, the gold content in the dump will be $1,800 \mathrm{mg} / \mathrm{m}^{3}$, which is almost 2 times higher than its content in the original sands. At $30 \%$ process loss, this value will be $2,400 \mathrm{mg} / \mathrm{m}^{3}$, etc.

In the field, it is not possible to identify the volumes of effel dumps of depleted placers. Anthropogenic formations are either reclaimed, or blurred by water flows. With a strict account of the volume of dumps and representative sampling with the identification of the gold content in them $\left(\mathrm{C}_{\mathrm{e}}\right)$, using the coefficient of sand effel content $\left(\mathrm{K}_{\mathrm{e}}\right)$ and the metal content in the initial sands $\left(\mathrm{C}_{\mathrm{s}}\right)$, it is possible to calculate the actual loss percentage $\left(\mathrm{L}_{\mathrm{act}}\right)$ (formula 1):

$$
\mathrm{L}_{\mathrm{act}}=\mathrm{C}_{\mathrm{e}} \times \mathrm{K}_{\mathrm{e}} / \mathrm{C}_{\mathrm{s}}
$$

In other cases, on the contrary, knowing the average gold content in the original sands, the percentage of process loss and the sand effel factor, it is possible to predict possible gold contents in effel heaps using formula 2 :

$$
\mathrm{C}_{\mathrm{e}}=\mathrm{L}_{\mathrm{act}} \times \mathrm{C}_{\mathrm{s}} / \mathrm{K}_{\mathrm{e}}
$$

On the one hand, this formula makes it possible to assess the resource potential of anthropogenic formations of the placer as a whole, on the other hand, to strictly control the annual data on gold loss at specific alluvial sites submitted by subsoil users. 


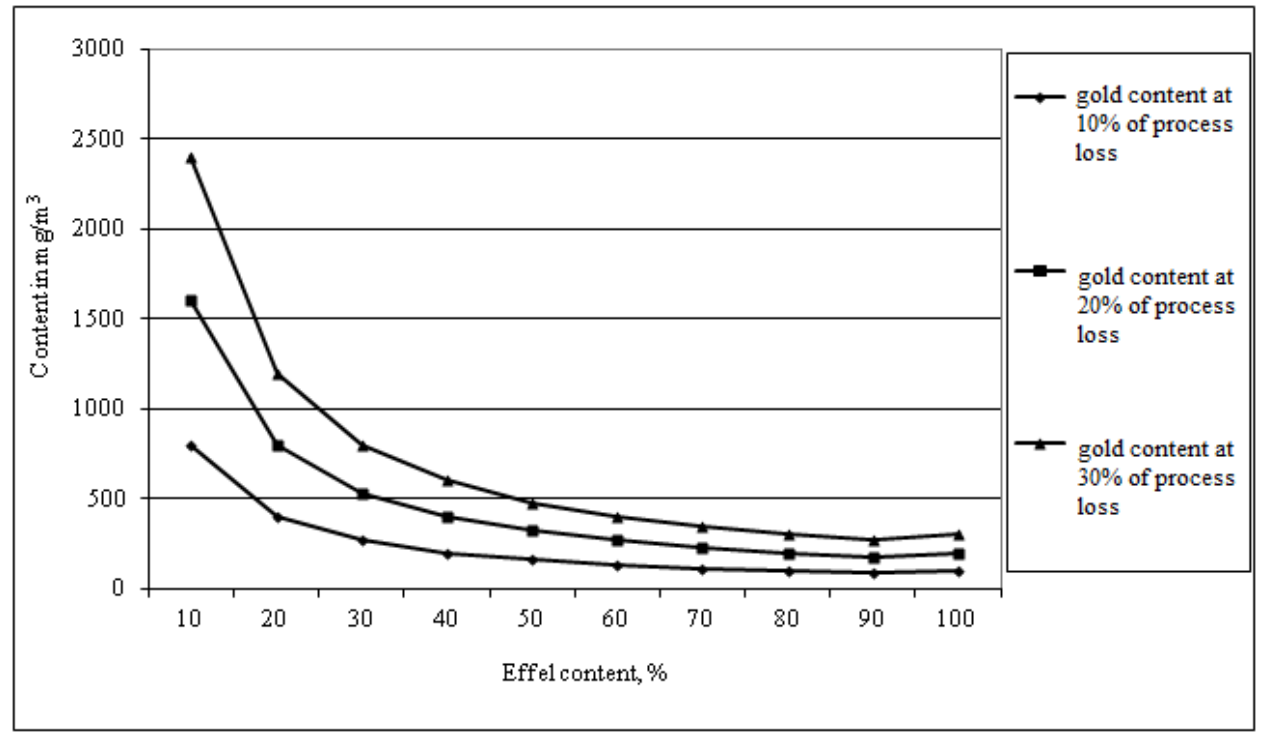

Fig. 1. Dependency of gold content in effel dumps on the effel content in sand at initial gold content in $1 \mathrm{~g} / \mathrm{m}^{3}$ of sand, daily washing of $1,000 \mathrm{~m}^{3}$ and process loss of $10 \%, 20 \%$ and $30 \%$.

So, according to the results of the study of the process sample (volume $2.5 \mathrm{~m}^{3}$ ) from the effel dump placer of the Leviy Creek (the Limuri River basin), the gold content was $3 \mathrm{~g} / \mathrm{m}^{3}$, with $60 \%$ extracted by gravitational method. According to the operational data, the placer had a useful component content in the initial sands of $6 \mathrm{~g} / \mathrm{m}^{3}$, effel content about $60 \%$, clayeyness of sands being insignificant $5 \%$, washability of sands being good, process loss about $10 \%$, heavy minerals were practically absent. Gold is small, often in the form of chats or with clay urges. Based on the available parameters (content, effel content, process loss) under normal conditions of washing, the gold content in the dumping site, according to the calculation by formula 2 should be close to $360 \mathrm{mg} / \mathrm{m}^{3}$. However, in this case, the figure an order of magnitude higher than the control one. Factors that determined such losses could be: the presence of clay material, the incorrect identification of the proportion of the effel component or the content of gold in the sands, i.e., the subsoil user knowingly submitted distorted information.

Thus, the granulometric composition of sands, on the one hand, has a direct effect, especially in the case of increased effel content, when a viscous sand-water flow is created. At the same time, changes in estimated process loss are insignificant. On the other hand, the effect of indirect or consequent-false, as in the example considered above, forms the "standard" appearance of a possible anthropogenic placer.

\subsection{Initial gold content in pillar sands}

Regions of Far East are significantly different natural and climatic conditions, so for the reserves of placer deposits located in different climatic conditions, particular specifications have been developed. For example, only in Khabarovsk Region, this indicator is divided into three economic areas - southern, central, northern. Accordingly, the minimal commercial metal content, which makes it possible to profitably develop placers in these areas, is significantly different. Taking into account the current gradations of the 
conditioning requirements and the minimal commercial gold content, placers and exposures of placers of Khabarovsk Region are divided into 5 groups (Table 1).

Table. 1. Proportion of placers in terms of gold content in the sands of different economic areas of Khabarovsk Region

\begin{tabular}{lcc|cccc}
\hline \multirow{2}{*}{$\begin{array}{c}\text { Economic } \\
\text { area }\end{array}$} & $\begin{array}{c}\text { No. of } \\
\text { placers }\end{array}$ & $\begin{array}{c}\text { Exposures of } \\
\text { placers }\end{array}$ & \multicolumn{4}{|c}{ Placer share in terms of gold content, \% } \\
\cline { 4 - 7 } & & $<0.2 \mathrm{~g} / \mathrm{m}^{3}, \%$ & $0.2-0.8$ & $0.9-2.0$ & $2.1-5.0$ & $>5$ \\
& & & $\mathrm{~g} / \mathrm{m}^{3}$ & $\mathrm{~g} / \mathrm{m}^{3}$ & $\mathrm{~g} / \mathrm{m}^{3}$ & $\mathrm{~g} / \mathrm{m}^{3}$ \\
Northern & 530 & 4.9 & 34.3 & 41.1 & 16.0 & 3.8 \\
Central & 217 & 3.0 & 37.6 & 32 & 19.3 & 8.1 \\
Southern & 42 & 16.7 & 23.8 & 35.7 & 9.5 & 7.0 \\
\hline
\end{tabular}

As can be seen from the table, the share of placers with concentrations of more than $2.1 \mathrm{~g} / \mathrm{m}^{3}$ in different economic areas varies from 16.5 to $27.4 \%$. These placers account for up to $62 \%$ (from 25.7 to $79 \%$ ) of reserves in Khabarovsk Region (Table 2). This indicator is highest in Ayano-Maysky, Okhotsky and Verkhnebureinsky districts of Khabarovsk Region.

Table 2. Distribution of gold reserves in the placers of Khabarovsk Region

\begin{tabular}{|c|c|c|c|c|c|c|}
\hline \multirow[t]{2}{*}{$\begin{array}{l}\text { Economi } \\
\text { c area }\end{array}$} & \multirow[t]{2}{*}{$\begin{array}{l}\text { No. of } \\
\text { placers }\end{array}$} & \multicolumn{5}{|c|}{$\begin{array}{l}\text { Share of reserves }(\%) \text { in placers with different gold content } \\
\text { in original sands, of the total in the area }\end{array}$} \\
\hline & & $\begin{array}{l}<0.2 \\
\mathrm{~g} / \mathrm{m}^{3}\end{array}$ & $\begin{array}{l}0.2-0.8 \\
\mathrm{~g} / \mathrm{m}^{3}\end{array}$ & $\begin{array}{l}0.81-2.0 \\
\mathrm{~g} / \mathrm{m}^{3}\end{array}$ & $\begin{array}{l}2.1-5 \\
\mathrm{~g} / \mathrm{m}^{3}\end{array}$ & $>5 \mathrm{~g} / \mathrm{m}^{3}$ \\
\hline Northern & 530 & 0.3 & 3.4 & 38.7 & 15.1 & 42.3 \\
\hline Central & 217 & 0.08 & 9.6 & 10.4 & 8.5 & 71.5 \\
\hline Southern & 42 & 2.3 & 40.6 & 4 & 24.8 & 0.9 \\
\hline TOTAL & 789 & & & 54.8 & 13.8 & 48.5 \\
\hline
\end{tabular}

The initial gold content in the sands, at first glance, does not have a direct effect on the volume of loss and is not used as an indicator in the calculation of process loss. But in practice it turns out that the higher the initial contents in the washed sands, the higher the share of actual metal loss and, accordingly, its absolute content in dumps. Perhaps this is due to a limited bed capacity of the $\log$ in the device. To avoid unnecessary losses in this case, it is possible to include in the process scheme a schedule of 2-3 times of washing-ups $[9,10]$. However, in reality, because of the additional loss of time and, accordingly, the reduction of the washing volumes, multiple washing-ups are practically not made. This problem can be solved by an extension of the logs, use of 2-3-band sluices, adding more sluices of small filling and other methods oriented to optimizing process schemes. Thus, high gold content in wash sands with non-compliance with process requirements lead to excess gold loss. Theoretically, it is assumed that the greatest correspondence between designed and real losses is achieved when washing the sands of those placers where the gold content is from 0.9 to $2.0 \mathrm{~g} / \mathrm{m}^{3}$. But there are observations when, against the background of more pronounced other factors that predetermine metal loss during the development of placers, the manifestation of this factor exacerbates their influence, causing high content of the useful component in anthropogenic objects. Experimental and methodological work on various alluvial objects confirmed that an increase in the initial contents in the sands to $5 \mathrm{~g} / \mathrm{m}^{3}$ and more determines a 2-fold increase in process loss [3].

It should be noted that the importance of the "primary content" factor can also be considered from other positions, in particular taking into account direct losses: the higher the gold content in the original sands, the greater its loss in quantitative terms, which is extremely important in assessing the resource potential of anthropogenic formations. Given 
the same values of the designed process loss and the comparability of the main placer's parameters, the high average gold content in the initial sands makes it possible to predict its increased contents in the dumping sites. Accordingly, one can expect in the northern areas of Khabarovsk Region, where placers with high minimum industrial contents are developed, higher gold content occurs in the dump sites. Theoretically, with the process losses identified at $10 \%$ with $80 \%$ of the sand's effel content, the gold content in dumps of placers can be as follows:

- 25-100 mg / $\mathrm{m}^{3}$ - with initial metal content in the sands of $0.2-0.8 \mathrm{~g} / \mathrm{m}^{3}$;

- 113-250 mg / $\mathrm{m}^{3}$ - with initial metal content in the sands of $0.9-2.0 \mathrm{~g} / \mathrm{m}^{3}$;

- up to $625 \mathrm{mg} / \mathrm{m}^{3}$ - with initial metal content in the sands of $2.1-5.0 \mathrm{~g} / \mathrm{m}^{3}$;

- over $625 \mathrm{mg} / \mathrm{m}^{3}$ - with initial metal content in the sands of $5.0 \mathrm{~g} / \mathrm{m}^{3}$.

In this case, a decrease in the share of the effel component can significantly increase the level of gold content in the dump sites and their resource attractiveness.

\section{Conclusions}

Thus, high gold content in the original sands combined with a low coefficient of efficiency (less than 50\%) cause the formation of highly promising anthropogenic placers of the dumping site with metal contents in them of at least $500 \mathrm{mg} / \mathrm{m}^{3}$. With the safety of the dump site and the presence of other positive parameters (volumes of rock mass, absence of reclamation) in the waste area of the alluvial deposit, it is possible to predict a new manmade placer meeting the standard requirements with a high degree of verification. When assessing the feasibility of identifying promising dump sites, analysis and consideration of these factors is mandatory, otherwise one will be limited to the forecast of man-made placers with $60-200 \mathrm{mg} / \mathrm{m}^{3}$, which significantly reduces the present possibility of involving highly prospective objects in re-development.

\section{Reference}

1. O.V. Zamyatin, B.K. Kavchik, Gold mining. Information and advertising bulletin. 52. 6$9(2-3)$.

2. V.A. Makarov, Gold and technology. 3 (13). $42-49$ (2011).

3.G.S. Mirzekhanov, Z.G. Mirzekhanova, Resource potential of anthropogenic formations of placer gold deposits (Moscow: MAKS Press 2013).

4. G.S. Mirzekhanov, Z.G. Mirzekhanova, Mine survey and subsoil use. 5(91).14-20 (2017).

5. I.Iu. Rasskazov, V.S. Litvintsev, G.S. Mirzekhanov, T.S. Banschikova, Subsoil use, XXI century. 1 (58). 46-55 (2016).

6. B.I. Benevolsii, Gold of Russia: Problems of use and reproduction of mineral and raw materials base. $2^{\text {nd }}$ ed., enlarged (Moscow: "Geoinformark", CJSC, 2002).

7. A.P. Sorokin, V.D. Glotov, Gold-bearing structural-material assemblages of Far East. Vladivostok (Dalnauka, 1997).

8. I.S. Litvinenko, I.S. Golubenko, Survey and protection of subsoil. 5.17-24 (2015).

9. S.M. Shorokhov, Technology and complex mechanization of development of alluvial deposits. (Moscow: Nedra, 1973).

10. I.I. Kovlekov, Anthropogenic gold of Yakutia. (Moscow: MSGU, 2002). 